\title{
Blunt Trauma Liver-Conservative or Surgical Management: A Retrospective Study
}

Sreeramulu PN*, Venkatachalapathy TS and Anantharaj

Department of Surgery, Sri Devaraj URS Medical College, Tamaka, Kolar, Karnataka, India

\begin{abstract}
Background: The liver is one of the most frequently damaged organs and remains the most common cause of death following blunt abdominal trauma. Currently, a conservative management constitutes the treatment of choice in patients with hemodynamic stability. The aim of this study is to evaluate the results of an operative and conservative management of 55 patients with liver injury treated in a single institution.
\end{abstract}

Methods: A retrospective study of the patients presented with blunt liver trauma was performed from 2008-2012. The patients were categorised according to the mode of treatment received. Group I: Conservative management; Group II: Operative management.

Variables analyzed included demographic data, cause of injury, grade of injury, associated injuries, vitals, haemoglobin values, mode of treatment and complications.

Results: A total of 55 patients were analyzed. 16 patients had sustained severe injuries. Mean pulse rate in conservative and operative group was 92 and 102 beats/min respectively.

Mean blood pressure in conservative and operative group was $110 / 70$ and 90/60 $\mathrm{mmHg}$ respectively. Conservative treatment was followed in 28 patients with surgery undertaken in 6 of the patients from this group due to failure of conservative treatment. Immediate surgery was carried out in 27 patients. Mortality occurred in 8 patients. Morbidity occurred among 5 patients in conservative group and among 8 patients in operative group. Mean duration of hospital stay in conservative and operative groups are respectively 17 and 19 days. $P$ value is significant (0.04).

Conclusions: Conservative treatment is an adequate treatment in mild to moderate liver injury patients. Failure of conservative treatment did not show a higher incidence of complications or mortality but it should be performed in centres with experienced surgeons.

Keywords: Liver trauma; Conservative management; Surgical treatment

\section{Introduction}

The relatively fixed position of the liver and its large size makes it more prone for injury in blunt trauma of the abdomen. Liver and spleen together, account for $75 \%$ of injuries in blunt abdominal trauma. Though liver is the second most commonly injured organ in abdominal trauma; it is the most common cause of death following abdominal injury. Compared to splenic injuries, management of liver trauma still remains a challenge in the best of trauma centres [1,2].

In the past, most liver injuries were treated surgically. However evidence confirms that about $86 \%$ of liver injuries have stopped bleeding by the time surgical exploration is performed and $67 \%$ of laparotomies done for blunt trauma abdomen are non-therapeutic. Imaging techniques especially Computerised Tomographic (CT) scan has created remarkable impact in managing liver trauma patients by reducing the number of laparotomies. About $80 \%$ of adults and $97 \%$ of children are presently managed conservatively worldwide at high volume trauma centres $[3,4]$.

The large size of the liver, the friable parenchyma, its thin capsule and its relatively fixed position make it prone to blunt injury. Right lobe is more often involved, owing to its larger size and proximity to the ribs $[5,6]$. Compression against the fixed ribs, spine or posterior abdominal wall results in predominant damage to segments 6,7 and 8 of the liver $(>85 \%)$. Pressure on right hemithorax may propagate through the diaphragm producing contusion of dome of right lobe of liver. Liver's ligamentous attachments to diaphragm and posterior abdominal wall act as sites of shearing forces during deceleration injury. Liver injury can also occur as a result of transmission of excessively high venous pressure to remote body sites at the time of impact. Weaker connective tissue framework, relatively large size and incomplete maturation and more flexible ribs account for higher chance of liver injury in children compared to adults.

Deceleration injuries producing shearing forces may tear hepatic lobes and often involve the inferior vena cava and hepatic veins. A steering column injury can damage an entire lobe. Liver trauma may result in subcapsular/intrahepatic hematomas, lacerations, contusions, hepatic vascular injury and bile duct injury. Most blunt trauma livers (80\% in adults and $97 \%$ in children) are treated conservatively $[7,8]$.

Conservative treatment mandates repeated clinical monitoring and surgical intervention if conservative treatment fails. A comparison of patients receiving operative and nonoperative treatment of liver

*Corresponding author: Dr. Sreeramulu PN, Professor, General Surgery, Sri Devaraj URS Medical College, Tamaka, Kolar, Karnataka, India, E-mail: drsreeramulupn@yahoo.in

Received September 26, 2012; Accepted October 17, 2012; Published October 19, 2012

Citation: Sreeramulu PN, Venkatachalapathy TS, Anantharaj (2012) Blunt Trauma Liver-Conservative or Surgical Management: A Retrospective Study. J Trauma Treat 1:146. doi:10.4172/2167-1222.1000146

Copyright: ( 2012 Sreeramulu PN, et al. This is an open-access article distributed under the terms of the Creative Commons Attribution License, which permits unrestricted use, distribution, and reproduction in any medium, provided the original author and source are credited. 
injuries has revealed no difference in the length of hospital stay, but requirements for blood transfusion and intra abdominal complications were significantly lower in those managed conservatively [9-11].

\section{Materials and Methods}

We herein review our experience in the treatment of liver trauma in adults over the last 5 years including all the patients diagnosed with hepatic injury reported in the registry of admittance to the Emergency Department of our Institution. The liver trauma was classified according to the Hepatic Injury Scale (HIS) of the American Association for the Surgery of Trauma.

To analyze the results the patients were divided into two groups, Group I: conservative treatment; Group II: operative treatment. The decision as to which treatment to apply depended on the surgeon, with conservative treatment being implemented in patients fulfilling the following criteria:

a) Hemodynamic stability or correct response to plasma volume expansion;

b) Transfusion requirements related to hepatic injuries of less than 2-3 red blood cell concentrates;

c) Absence of signs of diffuse peritonitis on physical examination;

d) Mild to moderate liver injury on imaging tests.

The initial radiological examination was carried out with ultrasonography or abdominal computerized tomography (CT) scan according to what was available at that time.

This group of patients remained under strict clinical control, hemodynamic monitorization, and seried determination of haemoglobin and absolute bed rest for a period of 48-72 hours. The appearance of hemodynamic instability, clinical signs of peritonism and/or a continued reduction in hematocrit values was considered as non-surgical treatment failure with surgery being thereby indicated. On confirmation of the absence of clinical changes and if the associated injuries so permitted, the patients were transferred to conventional hospitalization wards. Abdominal CT was routinely performed prior to hospital discharge and was repeated after 2-3 months to verify the resolution of the injuries and to authorize complete renewal of daily activities. Patients who did not fulfil any of the previously mentioned conditions were evaluated for immediate surgical treatment.

Variables analyzed included demographic data, cause of injury, grade of hepatic injury, associated injuries, vitals, haemoglobin values, and transfusion requirements, mode of treatment, complications and hospital stay.

\section{Results}

The mean age of the patients was of 30.41years (range 7-65 years) (Figure 1).

The injuries were due to traffic accidents (36), fall from height (13), and assault (06). Associated abdominal lesions were presented in 41.3 $\%$ of the cases: kidney (4), spleen (6), diaphragm (6), colon (2), small intestine (2) and others lesions (gallbladder, stomach) (2).

A total of $39.2 \%$ of the patients had presented extra abdominal lesions: thoracic injury (6), bone fractures (3), cranioencephalic trauma (3), pelvic (4) and vertebral lesion (5).

The classification of the severity of the hepatic injuries according to the AAST criteria was as follows,

\section{Grade I:}

1. haematoma: sub capsular, $<10 \%$ surface area

2. laceration: capsular tear, $<1 \mathrm{~cm}$ depth

\section{Grade II:}

1. haematoma: sub capsular, $10-50 \%$ surface area

2. haematoma: intraparenchymal $<10 \mathrm{~cm}$ diameter

3. laceration: capsular tear, $1-3 \mathrm{~cm}$ depth, $<10 \mathrm{~cm}$ length

\section{Grade III:}

1. haematoma: sub capsular, $>50 \%$ surface area, or ruptured with active bleeding

2. haematoma: intraparenchymal $>10 \mathrm{~cm}$ diameter

3. laceration: capsular tear, $>3 \mathrm{~cm}$ depth

Grade IV:

1. haematoma : ruptured intraparenchymal with active bleeding

2. laceration : parenchymal disruption involving $25-75 \%$ hepatic lobes or 1-3 Couinaud segments (within one lobe)

\section{Grade V:}

1. laceration: parenchymal disruption involving $>75 \%$ hepatic lobe or $>3$ Couinaud segments (within one lobe)

2. vascular: juxtahepatic venous injuries (IVC, major hepatic vein) (Figure 2)

\section{Surgical Treatment}

Twenty four patients underwent surgery on admission due to hemodynamic instability. Other causes for surgical treatment were: signs of peritoneal irritation on physical exploration, pneumoperitoneum, suspicion of diaphragmatic injury, renal injury and grade $\mathrm{V}$ radiologically diagnosed hepatic injury. Ten patients with hemodynamic instability required more than 5 red blood cell concentrates. Mean pulse rate and blood pressure were $102 \mathrm{bpm}$ and 90/60 $\mathrm{mm} \mathrm{Hg}$ respectively.

The surgical techniques performed included hepatorrhaphy in 12 cases, vascular suture in 2 cases, hepatic resection in 6 cases, packing in 2 cases and electro coagulation in 5 cases. Patients with packing had 2 avulsions and 5 lacerations, localized in right lobe of liver, all received

\section{Gender distribution}

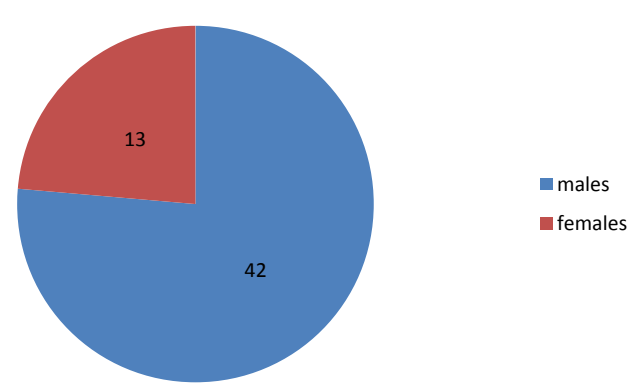

Figure 1: From April 2008 to April 2012, 55 patients (Males-42, Females-13) with liver trauma were treated in our centre. 


\section{Grades of injury}

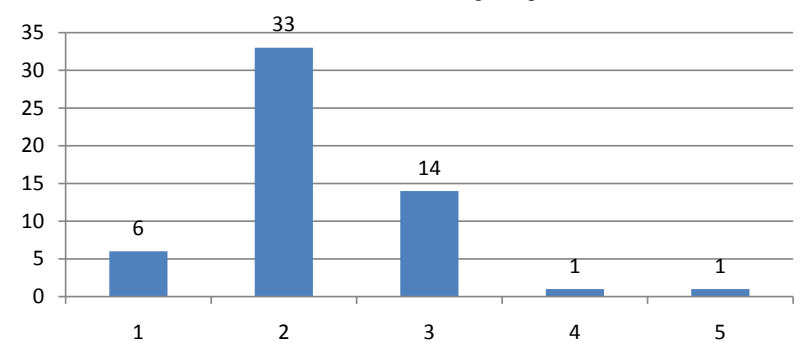

Figure 2: Grade VI: vascular hepatic avulsion. Grade I: 6 cases; Grade II: 33 cases; Grade III: 14 cases; Grade IV: 1 case; Grade V: 1 case.

more than 5 red blood cell concentrates. There were 5 deaths during the exploratory laparotomies.

Complications were presented in 8 patients, 2 cases related to surgery and 6 cases had respiratory complications. In the group receiving surgical treatment, the complications were: biliary leak in 1 case and wound infection in 1case. One patient was reoperated for biliary leak. The mean hospital stay in this group was 19.6 days.

\section{Conservative Treatment}

Twenty eight patients initially received conservative treatment that was effective in 22 cases. Mean pulse rate and blood pressure were 92 bpm and 110/70 $\mathrm{mm} \mathrm{Hg}$ respectively.

The morbidity occurred in 5 cases in this group. Complications on the patients who did well with the conservative treatment were a respiratory infection, one adult respiratory distress syndrome (ARDS) and one paralytic ileus with sepsis. The mortality in this group was of 3 patients. One died as a consequence of associated severe cranioencephalic trauma, one for multi organ failure and one patient died after failure of conservative treatment. The mean hospital stay of this group was of 17.03 days. The global rate of transfusion requirements in the non surgical treatment group was of $45.2 \%$ with red blood cell concentrates.

\section{Failure of Conservative Treatment}

In 6 patients, non surgical treatment failed with surgery being required. The reason for failure was hemodynamic instability in 4 cases and a maintained low hematocrit values in 2 cases. The patients were underdiagnosed after undergoing the complementary explorations, with grade $\mathrm{V}$ hepatic injuries going undiagnosed in 3 cases. Likewise, splenic lesions were not diagnosed leading to exploration in 3 cases. Two patients died, due to ARDS in one patient with severe cranioencephalic trauma, and the other death was due to nasocomial pneumonia with multi organ failure. The major complications were presented as respiratory distress and respiratory infections. Blood transfusion was required in 18 patients.

\section{Discussion}

In the last 15 years, the treatment of liver trauma has progressively evolved [4,12]. At the beginning of the 1990's several articles reported the possibility of non surgical treatment in patients with hemodynamic stability similar to what is carried out by paediatric surgeons in cases of hepatosplenic injuries $[9,12]$. The aim of this type of treatment is to not only decrease the number of non therapeutic laparotomies $[13,14]$ but also to achieve a reduction in the values of morbidity and mortality. In this group of patients immediate surgery is substituted by initial non surgical treatment with close patient supervision. Surgery is indicated in cases of continued haemorrhage or the suspicion of the presence of determined associated lesions. Fortunately, a high percentage of injuries, around $85 \%$, are not severe (HIS<grade IV) [4,15], which previously were treated with electrocoagulation, topical haemostatic agents or superficial ligature. In these injuries, the haemorrhage had ceased at the time of surgery in a considerable number of cases [16]. It is in this group of patients that conservative treatment undoubtedly achieves the greatest percentage of success. However, in the remaining $10 \%-20 \%$ of the severe hepatic injuries the decision as to whether surgery is necessary represents a difficult challenge for the surgeon.

Therapeutic evolution has become possible thanks to the diffusion of imaging techniques such as echocardiography and abdominal CT which are more rapid, sensitive and specific in the diagnosis of abdominal injuries $[2,12,14,17,18]$, and they have replaced peritoneal lavage because of its low specificity and bad prediction of the need for laparotomy [17], despite its high sensitivity and speed of application. In our case series, if the patient presents signs of hemodynamic instability, the patient was subjected for abdominal CT with endovenous contrast to provide better knowledge of the liver injury, HIS classification and the determination or discarding of associated intra abdominal injuries. CT scanning has become the gold standard for diagnosis of solid organ injury and allows reasonably accurate grading of organ injuries and provides crude quantitation of the degree of hemoperitoneum [12].

In the series published recently, the applicability of conservative treatment in patients with liver injury has varied from $35 \%$ to $82 \%[6,16]$ according to the year, the selection criteria and the number of patients studied. The two main variables guiding the therapeutic approach were hemodynamic instability and the need for transfusion [19-21]. In our centre conservative treatment was implemented in almost $50 \%$ of the cases in the last 5 years with a failure rate of $21 \%$, which is slightly higher than what has been reported in the literature [6].

There are no predictive criteria to allow either the selection of the type of adequate treatment or to predict the failure of conservative treatment. Thus, the application of conservative treatment in cases of liver trauma obliges the surgeon to perform continuous monitorization of the patient during the first 48 hours and to have adequate infrastructure to allow immediate surgery on observation of clinical deterioration of the patient [7]. During the first years most series limited the cases to non-severe injury (grade $\leq$ III) [5], restricting the use of conservative treatment to values below $40 \%$ of the cases. Later, the good results achieved led to progressive widening of the inclusion criteria [14].

Feliciano et al. proposed conservative treatment for any lesion regardless of the magnitude as long as the patient remained hemodynamically stable and with hemoperitoneum of less than $500 \mathrm{ml}$ as estimated by CT scan [22]. Currently most authors consider that the decisive factor in deciding the implementation of conservative treatment should be hemodynamic stability after initial recovery independently of the grade of the injury and the quantity of hemoperitoneum estimated by CT $[2,15,20]$. In the present series, one patient with grade $\mathrm{V}$ injury underwent surgery. In our limited experience severe grade $\mathrm{V}$ injuries appear to be a predictive factor requiring surgical treatment. Nonetheless, in a series of 500 patients who received conservative treatment, Malhotra et al. described a failure rate of only $23 \%$ in the group of patients $(n=30)$ with grade $\mathrm{V}$ lesions [16]. Other series show that nonoperative management of high-grade liver injuries have been successful [14] but is associated 
Citation: Sreeramulu PN, Venkatachalapathy TS, Anantharaj (2012) Blunt Trauma Liver-Conservative or Surgical Management: A Retrospective Study. J Trauma Treat 1:146. doi:10.4172/2167-1222.1000146

with significant morbidity and correlates with the grade of liver injury $[22,23]$. Complications require a multidisciplinary treatment and a strategy should be anticipated in grade IV and V injury [24]. Highgrade injuries can be managed nonoperatively, if operative intervention is not required for hemodynamic instability or associated injuries, with a low mortality $[4,14,15,25-27]$. In this subgroup with high risk of conservative treatment failure, the use of angiography with selective embolization of the hepatic injuries may be useful [4,28-30]. In our series none of the cases has been treated with selective embolization of hepatic artery due to lack of infrastructure. The main cause of the low use of angiography is that the majority of vascular injuries are venous [31]. The mortality from juxtahepatic venous injuries is generally reported from $50 \%$ to $80 \%$ and the direct approach is the correct attitude in these lesions [32]. It is important to emphasize that in our series the indexes of morbidity and mortality were not greater in the patients with conservative treatment failure compared to similar injuries in the surgical group with the values of both groups being similar to those reported by other groups $[16,33,34]$.

Our comparative study between the two groups shows a development in diagnosis and similar treatment displayed in the others paper. The use of Computerised Tomography as gold standard technique in diagnosis and the conservative treatment in stable patients with low consumption of blood products and even in high grade injuries (IV-V) are the principal conclusions in this and others multiple reports.

\section{Conclusion}

Conservative treatment of hepatic injury is applicable in patients presenting hemodynamic stability, although in grade $\mathrm{V}$ injuries there is a high risk of conservative treatment failure and, in our opinion, these patients should undergo surgical treatment after diagnosis. Failure of conservative treatment does not necessarily lead to an increase in the incidence of complications or mortality in centres with adequate infrastructure with monitorization and/or continued intensive therapy and the immediate possibility of performing surgery.

\section{References}

1. Feliciano DV (1989) Surgery for liver trauma. Surg Clin North Am 69: 273-284.

2. Parks RW, Chrysos E, Diamond $\mathrm{T}$ (1999) Management of liver trauma. Br J Surg 86: 1121-1135

3. Gallardo García M, Navarro Piñero A, Buendía Pérez E, Oliva Muñoz H, De la Fuente Perucho A, et al. (1991) Diagnostic and therapeutic assessment of liver trauma. Rev Esp Enferm Dig 79: 105-111.

4. David Richardson J, Franklin GA, Lukan JK, Carrillo EH, Spain DA, et al. (2000) Evolution in the management of hepatic trauma: a 25 -year perspective. Ann Surg 232: 324-330.

5. Pachter HL, Hofstetter SR (1995) The current status of nonoperative management of adult blunt hepatic injuries. Am J Surg 169: 442-454.

6. Carrillo EH, Richardson JD (2001) The current management of hepatic trauma. Adv Surg 35: 39-59.

7. Brammer RD, Bramhall SR, Mirza DF, Mayer AD, McMaster P, et al. (2002) A 10-year experience of complex liver trauma. Br J Surg 89: 1532-1537.

8. Jacobs IA, Kelly K, Valenziano C, Pawar J, Jones C (2001) Nonoperative management of blunt splenic and hepatic trauma in the pediatric population: significant differences between adult and pediatric surgeons? Am Surg 67: 149-154

9. Llado L, Jorba R, Pares D, Borobia FG, Biondo S, et al. (2005) Influence of the application of a management protocol in the treatment of blunt abdominal trauma. Cir Esp 72: 79-83.

10. Moore EE, Cogbill TH, Jurkovich GJ, Shackford SR, Malangoni MA, et al (1995) Organ injury scaling: spleen and liver (1994 revision). J Trauma 38: 323-324.
11. Gertler J, Degutis LC, Clay R, Garvey R, Baker CC (1986) Pitfalls in the diagnosis and management of blunt splenic trauma. Conn Med 50: 645-647.

12. Richardson JD (2005) Changes in the management of injuries to the liver and spleen. J Am Coll Surg 200: 648-669.

13. Lucas CE, Ledgerwood AM (2000) Changing times and the treatment of liver injury. Am Surg 66: 337-341.

14. Jover-Navalon JM, Ramos-Rodriguez JL, Montón S, Ceballos-Esparragón J (2004) Nonoperative management of blunt liver trauma: Selection and followup criteria. Cir Esp 76: 130-141.

15. Silvio-Estaba L, Madrazo-González Z, Ramos-Rubio E (2008) Current treatment of hepatic trauma. Cir Esp 83: 227-234.

16. Malhotra AK, Fabian TC, Croce MA, Gavin TJ, Kudsk KA, et al. (2000) Blunt hepatic injury: a paradigm shift from operative to nonoperative management in the 1990s. Ann Surg 231: 804-813.

17. Carrillo EH, Platz A, Miller FB, Richardson JD, Polk HC Jr (1998) Non-operative management of blunt hepatic trauma. Br J Surg 85: 461-468.

18. Cuff RF, Cogbill TH, Lambert PJ (2000) Nonoperative management of blunt liver trauma: the value of follow-up abdominal computed tomography scans. Am Surg 66: 332-336.

19. Rozycki GS, Shackford SR (1996) Ultrasound, what every trauma surgeon should know. J Trauma 40: 1-4.

20. González-Castro A, Suberviola Cañas B, Holanda Peña MS, Ots E, Domínguez Artiga MJ, et al. (2007) Liver trauma. Description of a cohort and evaluation of therapeutic options. Cir Esp 81: 78-81.

21. Schwab CW (2001) Selection of nonoperative management candidates. World J Surg 25: 1389-1392.

22. Feliciano DV (1992) Continuing evolution in the approach to severe liver trauma. Ann Surg 216: 521-523.

23. Kozar RA, Moore FA, Cothren CC, Moore EE, Sena M, et al. (2006) Risk factors for hepatic morbidity following nonoperative management: multicenter study. Arch Surg 141: 451-458.

24. Christmas AB, Wilson AK, Manning B, Franklin GA, Miller FB, et al. (2005) Selective management of blunt hepatic injuries including nonoperative management is a safe and effective strategy. Surgery 138: 606-610.

25. Coughlin PA, Stringer MD, Lodge JP, Pollard SG, Prasad KR, et al. (2004) Management of blunt liver trauma in a tertiary referral centre. $\mathrm{Br} \mathrm{J}$ Surg 91 : 317-321.

26. Gourgiotis S, Vougas V, Germanos S, Dimopoulos N, Bolanis I, et al. (2007) Operative and nonoperative management of blunt hepatic trauma in adults: a single-center report. J Hepatobiliary Pancreat Surg 14: 387-391.

27. Ciraulo DL, Luk S, Palter M, Cowell V, Welch J, et al. (1998) Selective hepatic arterial embolization of grade IV and $\mathrm{V}$ blunt hepatic injuries: an extension of resuscitation in the nonoperative management of traumatic hepatic injuries. $J$ Trauma 45: 353-358.

28. Hagiwara A, Murata A, Matsuda T, Matsuda H, Shimazaki S (2002) The efficacy and limitations of transarterial embolization for severe hepatic injury. J Trauma 52: 1091-1096.

29. Mohr AM, Lavery RF, Barone A, Bahramipour P, Magnotti LJ, et al. (2003) Angiographic embolization for liver injuries: low mortality, high morbidity. Trauma 55: 1077-1081.

30. Buckman RF Jr, Miraliakbari R, Badellino MM (2000) Juxtahepatic venous injuries: a critical review of reported management strategies. J Trauma 48 978-984.

31. Polanco P, Leon S, Pineda J, Puyana JC, Ochoa JB, et al. (2008) Hepatic resection in the management of complex injury to the liver. J Trauma 65: 1264 1269.

32. Sanchez J, Seco JL, Aguado JM, Velasco F, Santamaría JL (1993) Hepatic trauma: treatment and prognostic factors. Cir Esp 54: 237-241.

33. Gonzalez J, Navarrete F, Alvarez JA, Aza J (1990) Hepatic trauma. Risk factors and treatment. Cir Esp 48: 666-671.

34. Ochoa L, Merck B, Geli S, Díaz de Liaño A (1991) Hepatic trauma $(90$ consecutive cases treated in 9 years. Rev Esp Enferm Dig 79: 393-396. 